\title{
Non A, non B hepatitis in the aged
}

\author{
M. Sonnenblick, ${ }^{1}$ R. Oren ${ }^{2}$ and R. Tur-Kaspa ${ }^{2,3}$ \\ ${ }^{1}$ Department of Geriatrics, Shaare Zedek Medical Center, ${ }^{2}$ Department of Medicine A and ${ }^{3}$ the Liver Unit, \\ Hadassah University Hospital, Jerusalem, Israel
}

\begin{abstract}
Summary: In order to study the clinical picture of non A, non B hepatitis in the elderly, a retrospective study was carried out in the two main hospitals in Jerusalem. Thirty-six patients with acute viral hepatitis, older than 65, have been hospitalized between the years 1982-1988. Seventy-two percent were diagnosed as non A, non B hepatitis. All patients were symptomatic and the main symptoms were abdominal pain, fever and jaundice. Thirty percent of the patients had marked cholestasis, while the disease was uneventful in $96 \%$ of the cases. Non A, non B hepatitis is the main type of viral hepatitis in the aged and should be suspected in patients with abdominal pain, fever and cholestasis.
\end{abstract}

\section{Introduction}

Sporadic viral hepatitis has been discussed little in the geriatric literature. Hepatitis A occurs mainly in children and young adults. It has been suggested that elderly patients have a more severe form of this disease especially during epidemics. Hepatitis B has usually been described in elderly people in connection with blood transfusions. ${ }^{1}$ In the recent years there has been an increased number of publications dealing with the features of non A, non B hepatitis. ${ }^{2-4}$ In order to define the characteristics of acute non A, non B hepatitis we have studied retrospectively the specific manifestations of this disease in the aged.

\section{Patients and methods}

The study has been conducted in the two main hospitals in Jerusalem; Shaare Zedek Medical Center and Hadassah University Hospital. Thirtysix patients older than 65 were diagnosed as suffering from acute viral hepatitis in the years 1982-1988.

The diagnosis of acute hepatitis was based on the history, clinical picture and liver function tests. Patients were excluded if they had a history of chronic liver disease, drug exposure, including the possibility of halothane-induced hepatitis or alcohol abuse. All patients with cholestasis and fever

Correspondence: R. Tur-Kaspa, M.D., Department of Medicine A, Hadassah University Hospital, Ein Kerem, Jerusalem, Israel.

Accepted: 3 January 1990 underwent ultrasonography examination of the biliary tract. All patients had serological tests for hepatitis A (HA), hepatitis B (HB), cytomegalovirus (CMV) and Epstein Barr virus (EBV). Hepatitis A infection was determined if the patient had antiHA IgM antibodies in the serum (solid phase RIA). Hepatitis B was diagnosed if the patient had HBsAg (RIA) and anti-HBcAg IgM antibodies (ELISA). The diagnosis of non A, non $B$ was made by exclusion of HA, HB and either EBV or CMV infection (as determined by IgM antibodies using direct immunofluorescence).

The patients' files were identified by personal review of the medical records and by computer. For all subjects identified, the medical records were reviewed and the following data were extracted: demographic characteristics, underlying disease, predisposing factors for liver disease, clinical symptomatology, laboratory workup including immunological identification or hepatotrophic viruses (HAV, HBV, EBV , CMV), the treatment given and the outcome.

The clinical and laboratory findings of the elderly patients with non A, non B hepatitis $(n=26)$ were compared to those of a group of 26 young patients aged 18-38 diagnosed as having acute non A, non B hepatitis.

\section{Results}

Thirty-six patients with acute viral hepatitis over the age of 65 were studied. The age ranged between $65-90$ years (mean 77 ). Fifteen out of $26(58 \%)$ were male and $11(42 \%)$ were females. 
As shown in Table $\mathrm{I}$, seven patients had acute viral hepatitis type $B$, two had evidence of CMV infection and one patient had EBV infection. There was not a single case of acute hepatitis $A$ in this age group. Twenty-six $(72 \%)$ had non A, non B hepatitis, $11(42 \%)$ had acquired the disease parenterally (post-transfusion), while $15(58 \%)$ had the sporadic type of non A, non B hepatitis. The incubation period in the post transfusion hepatitis cases was 4-16 weeks.

All patients were symptomatic. The symptoms and signs of the patients with non A, non B hepatitis are shown in Table II. Main symptoms were abdominal pain in $38 \%$ and jaundice in $30 \%$. Nine $(34 \%)$ had high temperature as a presenting symptom. In all these patients, ultrasonography examination excluded biliary tract disease. There was no evidence for bacteraemia in any of the patients who had high temperature.

The main laboratory values of the patients with acute non A, non B hepatitis are presented in Table III. Mean level of alkaline phosphatase was 430 units (normal < 110). Mean level of alanine aminotransferase (ALT) was 480 units (normal $<50$ ). Eight patients $(30 \%)$ had evidence of intrahepatic cholestasis which was more significant than the hepatocellular damage. In this group mean alkaline phosphatase level was 530 units while mean ALT was only 306 units. Comparing the aged patients with a young group of patients (26 patients aged $18-38$ ), in the younger group mean alkaline phosphatase level was only 340 units while mean ALT

Table I Aetiology of viral hepatitis in 36 elderly patients

\begin{tabular}{lrr}
\hline Virus & Number & $(\%)$ \\
\hline A & 0 & $(0)$ \\
B & 7 & $(19)$ \\
Non A, non B & 26 & $(72)$ \\
EBV & 1 & $(3)$ \\
CMV & 2 & $(6)$ \\
\hline
\end{tabular}

EBV - Epstein Barr virus; CMV - cytomegalovirus.

Table II Symptoms and signs of 26 patients with non A, non $B$ hepatitis

\begin{tabular}{lrr}
\hline & Number & $(\%)$ \\
\hline Fever & 9 & $(34)$ \\
Abdominal pain & 10 & $(38)$ \\
Jaundice & 8 & $(30)$ \\
Anorexia & 5 & $(19)$ \\
Nausea, vomiting & 3 & $(11)$ \\
Pruritus & 2 & $(8)$ \\
Diarrhoea & 1 & $(4)$ \\
Hepatomegaly & 9 & $(34)$ \\
\hline
\end{tabular}

Table III Laboratory tests of 26 patients with non A, non $B$ hepatitis

\begin{tabular}{lrr}
\hline & Number & $(\%)$ \\
\hline Bilirubin up to $17 \mu \mathrm{mol} / 1$ & 18 & $(69)$ \\
Bilirubin $18-91 \mu \mathrm{mol} / 1$ & 6 & $(23)$ \\
Bilirubin $91-400 \mu \mathrm{mol} / 1$ & 2 & $(8)$ \\
ALT level up to 200 units & 9 & $(37)$ \\
ALT level 200-600 units & 11 & $(40)$ \\
ALT $>600$ units & 6 & $(23)$ \\
ALP up to 200 units & 6 & $(23)$ \\
ALP 200-400 units & 7 & $(27)$ \\
ALP $>400$ units & 13 & $(50)$
\end{tabular}

ALT - alanine aminotransferase; ALP - alkaline phosphatase.

was 1140 units. Mean white blood cell count was $6.3 \times 10^{9} / 1(4.4-10.8)$.

Follow-up of the patients for 2-4 months (mean 3 ) revealed that only one patient died of fulminant hepatitis, while all the other 25 patients recovered clinically and biochemically. As chronic non A, non B hepatitis is known to have a fluctuant course, this period of follow-up is insufficient to draw any conclusions regarding chronicity.

\section{Discussion}

The results presented in this study indicate that non A, non B hepatitis is the main type of acute hepatitis seen in hospitalized patients older than 65 . In our study there was no case of elderly patients with acute HA infection. Nineteen percent had hepatitis B, while $72 \%$ of the patients had non A, non B hepatitis. Since many cases of non A, non B hepatitis are asymptomatic, it is reasonable to assume that this number is an underestimation of the proportion of non A, non B hepatitis among such patients in the population. ${ }^{5}$ The clinical manifestations of non A, non B hepatitis have been reviewed in both post-transfusion hepatitis, sporadic and epidemic cases. In general, acute non $\mathbf{A}$, non B hepatitis is a mild disease, jaundice is observed in only $25 \%$ of patients, ${ }^{6}$ fever is uncommon and the mean peak serum ALT level is 800 units. $^{\text {? }}$

To the best of our knowledge, this is the first report defining the clinical and biochemical characteristics of acute non A, non B hepatitis in the elderly. There are few reports concerning acute viral hepatitis in the aged and none of them specified non A, non B hepatitis. Fenstel et al. ${ }^{8}$ have described 23 elderly patients with viral hepatitis, without determining the aetiological virus. It was emphasized in their report that $50 \%$ of their patients had fever as a presenting symptom. Other clinical and biochemical manifestations showed no 
particular difference from the younger population. In our series of patients with acute non A, non B hepatitis, it is noteworthy that fever, right upper abdominal pain and jaundice were present in about one third of the patients. Moreover, $30 \%$ of the patients had evidence of marked impairment of the cholestatic functions as manifested mainly by a high level of alkaline phosphatase ( $>400$ units). Cholestasis is usually not a significant manifestation of acute non A, non B hepatitis. In the control young group of patients with non $A$, non $B$ hepatitis, the hepatocellular damage dominated the biochemical findings. Eighteen out of the 36 patients $(50 \%)$ with acute viral hepatitis had acquired the disease non-parenterally. Eighty-three percent of patients in the sporadic type of viral hepatitis had non A, non B. These findings are in contrast to the findings in the general population in Israel where $70 \%$ of the non-post transfusion cases are due to HA infection, $12 \% \mathrm{HB}$ and about $15 \%$ are due to non $A$, non B infection. ${ }^{9}$

In 1988, the agent of the blood-borne non A, non

\section{References}

1. Hyans, D.E. \& Fox, R.A. Gastrointestinal system - the liver and biliary system. In: Brocklehurst, J.C. (ed.) Textbook of Geriatric Medicine and Gerontology. Churchill Livingstone, New York, 1985, pp. 557-588.

2. Dienstag, J.L. Non-A, non-B hepatitis. I. Recognition, epidemiology and clinical features. Gastroenterology 1983, 85: 439-462.

3. Robinson, W.S. The enigma of non-A, non-B hepatitis. J Inf Dis 1982, 145: 387-395.

4. Shih, J.W., Esteban, Mur, J.I., Alter, H.J. Non A, non B hepatitis: advances and unfulfilled expectations of the first decade. In: Popper, H. \& Shaffner, F. (eds) Progress in Liver Diseases, Vol. 3. Grune \& Stratton, New York, 1986, pp. 433-452.

5. Alter, H.J. The dominant role of non-A, non-B in the pathogenesis of post-transfusion hepatitis: a clinical assessment. Clin Gastroenterol 1980, 9: 155-170.
B hepatitis was described by Houghton et al. ${ }^{10}$ Antibody to this agent (hepatitis $C$ virus) appears in the circulation between one and three months after onset of acute illness. Serological evidence for hepatitis $\mathrm{C}$ virus infection can be detected in $60-90 \%$ of cases of transfusion-associated hepatitis and $50 \%$ cases of sporadic non A, non B cases. Although this test is important in chronic cases, the frequency of anti-hepatitis $C$ virus in patients with acute, self limited non A non B hepatitis as in most of our patients, is substantially lower, approximately $15 \% .^{11}$

In conclusion, non A, non B is the main aetiology for acute viral hepatitis in the aged in Israel. In the elderly patients the symptoms and biochemical findings mimicking gall bladder or pancreatic disease, were evident. Acute non A, non B hepatitis should be considered in the differential diagnosis of elderly patients with clinical and biochemical findings that can mimic gall bladder and pancreatic disease.

6. Aach, R.D. \& Kahn, R.A. Post-transfusion hepatitis: curren perspectives. Ann Intern Med 1980, 92: 539-546.

7. Berman, M., Alter, H.J., Ishak, K.G., Parcell, R.H. \& Jones, E.A. The chronic sequelae of non-A, non-B hepatitis. Ann Intern Med 1979, 91: 1-6.

8. Fenstel, L.F. Viral hepatitis in the elderly. Gastroenterology 1965, 49: 262-271.

9. Shalit, M., Tur-Kaspa, R., Adler, R., Manny, N., Shraga, S. \& Eliakim, M. Non-A, non-B hepatitis not following transfusion. Isr J Med Sci 1982, 18: 986-989.

10. Choo, Q.L., Kuo, G., Weiner, A.J., Overby, L.R., Bradley, D.W. \& Houghton, $M$. Isolation of a cDNA clone derived from a blood-borne non-A, non-B viral hepatitis genome. Science 1989, 244: 359-362.

11. Kuo, G., Choo, Q.L., Alter, H.J. et al. An assay for circulating antibodies to a major etiologic virus of non-A non-B hepatitis. Science 1989, 244: 362-364. 